\title{
PONTOS DE VISTA SOBRE A DESCOLONIZAÇÃO EM MOÇAMBIQUE
}

\author{
José Luís Cabaço. Moçambique: identidade, colonialismo e libertação. São \\ Paulo, Editora da Unesp, 2009. 360 páginas.
}

\section{Peter Fry}

Escrever sobre a obra de um admirado amigo é uma das tarefas mais delicadas. Rasgar elogios pode soar parti pris, enquanto tecer criticas pode parecer dor de cotovelo. Em vez de fugir do desafio, resolvi aproveitar da amizade para, a partir de eventuais diferenças e semelhanças de interpretação, refletir sobre a autoria, a história e a antropologia.

Como reza o título, este livro extraordinário de José Luiz Cabaço, que ganhou o prêmio Anpocs de melhor tese de doutorado em 2008, é uma análise do processo de Independência de Moçambique, começando com uma caracterização da colonialismo português, passando pela tentativa da resistência da ditadura portuguesa aos ventos de mudança da década de 1960, pela formação da Frente de Libertação de Moçambique (Frelimo), pela guerra de independência, pela tomada do poder, seguindo a Revolução dos Cravos de 1974 e, por fim , pela opção de um regime socialista.
Cabaço começa com uma contundente crítica ao colonialismo português, o enorme abismo entre a retórica portuguesa da assimilação e não racismo e o racismo violento da ordem colonial moçambicana, que, ele argumenta, foi essencialmente dualista, fundada na oposição entre colonizadores e colonizados; brancos e negros. A miscigenação que ocorria sobretudo na província de Zambézia, onde os primeiros colonizadores estabeleceram alianças de casamento com as filhas dos potentados locais, cedeu, nos finais do século XIX, a um regime cada vez mais racializado, dividido entre aqueles que os portugueses denominavam "indígenas" e os "não indígenas".

Com os ventos de mudança na África e a paulatina independência das colônias francesas e inglesas no continente, o governo do ditador Antonio de Oliveira Salazar fincou pé, recusando peremptoriamente a abrir mão do seu império. Ressusci- 
tando o velho adágio da miscigenação, Salazar foi buscar no luso-tropicalismo de Gilberto Freyre a inspiração acadêmica de que precisava. Assim, argumenta Cabaço, e com razão, o luso-tropicalismo veio para sustentar a ideia de que o colonialismo português, por ser diferente dos outros, não deveria ceder às demandas por independência dos partidos nacionalistas que lutavam em toda a África de língua portuguesa a partir da década de 1960 . O governo de Salazar reivindicou a especificidade do colonialismo português a tal ponto que as colônias foram chamadas de províncias portuguesas, no ultramar com certeza, mas nem por isso menos portuguesas! Cabaço disseca os textos freyreanos que sustentaram a posição portuguesa, mostrando sua inconsistência histórica e lógica, acrescentando o interessantíssimo fato de que tiveram pouquíssimo impacto sobre a província de Moçambique. Como os demais países europeus tampouco levaram a sério essas ideias, parece que tiveram ressonância mesmo apenas entre a elite governamental da metrópole que as propagava.

O livro passa então para a análise do surgimento da Frente de Libertação de Moçambique, e a elaboração de um projeto de nação durante a guerra contra as forças portuguesas, bem como a reação dos colonos brancos neste período, que inclui uma fascinante exposição sobre a posição de alguns colonos brancos e seus aliados negros sob a liderança do carismático colono Jorge Jardim, que procurou evitar a derrota para a Fremilo e ao mesmo tempo, escapar do domínio da metrópole, esboçando uma independência autodeclarada em moldes "brasileiros" por assim dizer, voltando inclusive, às ideias de cooperação e convivência inter-racial presentes na ideologia do luso-tropicalismo.

Ao mesmo tempo, a própria Fremilo não escapava de dissensões internas. Houve certo conflito de perspectiva entre os militantes fora de Moçambique, com uma experiência predominantemente rural, e os quadros urbanos dentro de Moçambique, o que Cabaço denomina a revolta rural e o protesto urbano. Havia muitas diferenças entre as duas perspectivas, mas talvez a mais importante tenha sido suas atitudes para com a "cultura tradicional" das diversas etnias que coexistiam no país, e em particular com as ditas autoridades tradicio- nais. Enquanto os membros da revolta rural enxergavam a luta de independência como uma luta racial, fundada em tradiçôes locais, os jovens militantes de origem urbana pensavam a guerra como uma luta não contra os portugueses como raça, mas contra o colonialismo do qual nem todos os portugueses foram protagonistas. Posicionaram-se contra as autoridades tradicionais, que eram vistas como criação do governo colonial, e a favor de uma ordem universalista fundada no "homem novo" socialista.

A ineficácia da oposição militar à Fremilo e a Revolução dos Cravos viabilizaram a formação do primeiro governo independente, cuja liderança pertencia à Frente de Libertação de Moçambique, que defendia uma visão socialista para o novo país. Cabaço argumenta pela "coerência de propósitos [da Fremilo]: militares, econômicos, sociais, culturais e revolucionários" e termina falando da opção socialista que surge, "situada no seu tempo, como resultado das circunstâncias e condicionalismos que marcaram o processo emancipador”. Tratava-se da vitória não apenas da Frente de Libertação. mas também da perspectiva "urbana" modernizante ali existente.

Tive reaçôes diversas ao longo da minha leitura do livro de José Luis Cabaço. Como alguém que sustentava a existência de diferenças significativas entre o colonialismo português e o inglês, fiquei gravemente tocado pelo correto argumento de que o racismo e o abismo entre brancos e negros eram constitutivos desses dois tipos de colonialismo.

Num outro momento, preferiria que o autor tivesse relativizado o conceito de emancipação. Afinal, poder-se-ia argumentar que enquanto os moçambicanos se emanciparam do governo colonial português, no sentido de alcançar a independência política, não deixaram de serem submetidos, em seguida, a outras formas de controle governamental coercitivo. A opção socialista da Fremilo produziu um regime altamente centralizador, planejador e, talvez, até mais insistente na sua "verdade" socialista do que os colonos portugueses tinham sido com seu catolicismo. Como tenho argumentado, não consigo ver tanta diferença entre a política de assimilação dos portugueses durante o "tempo colonial” e a política de conversão dos moçambicanos 
em novos homens socialistas ao longo do "tempo Samora". A primeira produziu uma pequena elite negra e mestiça católica e letrada, ao passo que a segunda também produziu uma pequena elite, só que de dirigentes denominados "estruturas". Este regime também foi visto por muitos como opressor. Mais tarde, após uma violenta guerra interna, incentivada pelo regime de apartheid da África do Sul, o regime socialista deu lugar ao que se convenciona chamar de um regime neoliberal.

Hoje é lugar comum nas ciências sociais que o ponto de vista dos diversos nativos surge a partir do ponto de vista dos demais nativos que escrevem sobre eles. Quando o autor é nativo nos dois sentidos, a questão se complica.

Muitos anos atrás, quando Carlos Vogt e eu pesquisávamos a pequena comunidade negra de Cafundó no Estado de São Paulo e a sua língua africana, acabamos, como é comum em pesquisa do tipo "observação/participante", nos tornando personagens da história que contávamos. Nossa participação em tornar mais conhecida a língua africana e nossa mediação com o Estado no sentido de fazer valer alguns direitos fizeram com que sentíssemos a necessidade de nos incluir no relato que publicamos. "O relato que aqui será feito", escrevemos, "é o de um narrador cientista que, interessado em relativizar o comportamento do outro, se descobre ele próprio relativizado diante desse comportamento. Um relato cujo narrador em terceira pessoa dá lugar a um narrador em primeira pessoa, isso é, a um narrador-personagem" (Vogt e Fry, 1996, p. 20).

No final da sua introdução ao livro, José Luis Cabaço comenta que foi testemunha "direta e participante". Observa que isso "introduziu óbvias dificuldades da distanciação que uma análise científica requereria. $\mathrm{O}$ fato de ter redigido o texto longe do meu país, me ajudou nesse esforço, mas, 'observador participante' que fui de muitos desses eventos, considerei material útil para o trabalho alguns elementos de minha experiência pessoal e, nesses casos, optei por sinalizá-los de forma explícita”. Uma dessas sinalizações aparece quando o autor comenta en passant que em 1971, no auge da guerra de independência, era vice-presidente na sede de Maputo da Associação dos Naturais de Moçambique.
Pedi ao autor mais informações a este respeito. E sua resposta oferece uma pequena janela para ver o quanto José Luis Cabaço foi personagem importantíssima na história que narra, fundamentada em sua extraordinária memória para eventos, pessoas e posiçōes etc.:

A Associação dos Naturais de Moçambique era uma associação principalmente de brancos naturais da colônia, mas que aceitava gente de todas as cores (havia alguns indianos e mulatos e uns poucos assimilados). $\mathrm{Na}$ ANM sempre pairou um sentimento autonomista, o qual, em certos períodos históricos, se exacerbou em sonhos "brasileiros". Em finais de 1960, seu órgão informativo, Voz de Moçambique (VM), uma publicação mensal, foi "tomado" por alguns intelectuais (Eugénio Lisboa, Rui Knofli, Adrião Rodrigues etc.) opositores ou pelo menos críticos do regime. A Voz era principalmente um órgão literário, mas tinha colunas de opinião e de debate sobre questôes nacionais e internacionais. Nas entrelinhas residiam as principais críticas e questionamentos. Quando cheguei a Moçambique para fazer o meu trabalho para a Fremilo apercebi-me disso e do fato de que aumentava o número de jovens universitários que se aproximavam da ANM e da VM. Decidi, portanto, aproximar-me da associação, na época presidida por uma notável figura, o Eng. Homero Branco, conhecido pelas suas firmas posições a favor dos interesses de Moçambique, ainda que defendidas no âmbito da legalidade colonial e do qual eu era amigo. Interessava-me compreender que tipo de ideias autonomistas se desenvolviam naquele contexto, tanto entre os consagrados (muitos deles ligados ao grupo dos Democratas de Moçambique), mas sobretudo entre os jovens. No fim de 1972 terminava o mandato da Direção e haveria novas eleições. Homero Branco falou comigo e convidou-me a integrar, como um dos vice-presidentes, uma lista presidida por Jorge de Abreu, outro branco nascido em Moçambique com passado autonomista (embora mais próximo dos centros 
de poder) e claramente um "brasileirista" (You know what I mean!). Aceitei, até porque vi que da lista dos vice-presidentes fazia parte um economista negro que eu conhecia então superficialmente e que queria conhecer melhor: Mário da Graça Fernandes Machungo. Assim fiquei vice-presidente no biênio 1973/1974 (que não terminaria por conta dos desenvolvimentos políticos). Minha intuição foi correta, porque no mandato de que fiz parte um grupo de beirenses reanimou a ANM lá. E esse grupo de jovens empresários (a maioria filhos de velhos colonos,. empresários de sucesso) defendia uma independência de Moçambique alternativa à Fremilo, e eram muito próximos (penso que alguns deles ligados efetivamente) com o projeto Jorge Jardim. O mais interessante, Peter, é que mais tarde descobri que Machungo aceitara a outra vice-presidência pelas mesmas razóes: estar dentro e conhecer possíveis projetos alternativos de inspiração "smithiana". Enquanto fomos vice-presidentes juntos tornamo-nos amigos (com as famílias) mas sem sabermos que trabalhávamos ambos para a Fremilo...

Quando você e eu nos conhecemos, em 1989, eu era, desde o IV Congresso da Frelimo, membro eleito do secretariado do Comitê Central. Este era, como você sabe, o órgão executivo do partido; fui inicialmente secretário de Quadros e Formação. Quando Samora morreu e Chissano foi para a direção, passei formalmente para secretário-adjunto das relaçóes exteriores, porque Chissano acumulava as funções de secretario das relações exteriores com as de presidente do partido (que era o secretário-geral). $\mathrm{Na}$ prática, fui, nesse período, o secretário em exercício do pelouro e foi nessas condições que nos conhecemos.

No governo, a minha trajetória foi também confusa: nomeado em setembro de 1974 secretário de Estado do Trabalho (Mariano Matsinha, como ministro) do governo de transição, tive de passar a ministro da Informação, (tinha acabado de ser "editor" do Notícias, após o 25 de abril)substituindo Oscar Monteiro, que ficara doente. Ali estive até à Independência. No primeiro governo ocupei a pasta de ministro dos Transporte e Comunicações. Em 1977 (III Congresso) fui eleito para o Comitê Central do Partido Frelimo. Em maio de 1980 (logo depois da Independência do Zimbabwe) passei para ministro da Informação. No IV Congresso do Partido fui reeleito para o Comitê Central e, pelo Congresso, eleito para o secretariado, funções que desempenhei em acumulação com o Ministério até maio de 1986, quando deixei as minhas responsabilidades no governo para ficar full time no partido. Em 1991 escrevi uma carta ao presidente do partido anunciando para agosto o abandono do lugar, porque no $\mathrm{V}$ Congresso não mais me candidataria, desligando-me da política ativa.

Esse depoimento deixa mais do que claro que o autor foi participante ativíssimo antes de depois da Independência. É significativo, sem dúvida, o fato de ele ter abandonado a Fremilo um ano depois da promulgação da nova Constituição em Moçambique, que marca o fim da era socialista.

Cheguei em Moçambique após uma experiência prévia de pesquisador na Rodésia racista na década de 1960 e de muitos anos como professor de antropologia no Brasil. Não fui na condição de participante interno, mas como integrante da legião de fundações e governos que correram para participar no desenvolvimento de Moçambique. De 1989 a 1993, representava a Fundação Ford em Moçambique, com a responsabilidade de pensar a melhor maneira de aplicar recursos financeiros no sentido de aumentar a autonomia dos moçambicanos na passagem da guerra para paz, do socialismo para o que chamávamos de "democracia de mercado”. No início desse período apresentei-me a José Luis Cabaço, que naquela conjuntura era o secretário para Relações Exteriores do Partido Frelimo. Logo percebi que estava na presença de um homem cordial com um imenso conhecimento do seu país e dotado de um otimismo realista. Com o tempo tornamo-nos amigos e a ele devo muito do que aprendi sobre seu país. Mas também fui influenciado pelos jovens moçambicanos que vieram estudar no Rio de Janeiro e que tinham uma visão crítica do regime socialista (Fry, 2001). 
Como argumentei anteriormente, foi em Moçambique que vi com maior clareza a diferença entre as sequelas da colonização portuguesa e inglesa. Acabei concordando com Gilberto Freyre na sua Aventura e rotina (1953), quando delineia o que considera o cerne dessas diferenças, sem, neste livro, sugerir tendências hereditárias dos portugueses!

Evidentemente, é o Freyre após sua aliança com Salazar, quando considera os portugueses inerentemente humanistas na sua missão cristã e civilizadora, que foi o principal alvo da fúria dos anti-imperialistas (eu inclusive) e da crítica contundente de Cabaço. O caminho mais claro para criticar o essencialismo de Freyre era, e ainda é, a denúncia do imenso abismo entre a retórica luso-tropical e a realidade do racismo renitente.

Penso que os dois pontos de vista, juntos, se aproximam a uma boa interpretação dos acontecimentos. A retórica luso-tropicalista em Moçambique, assim como a noção de democracia racial no Brasil, pretendia negar o racismo e a segregação racial. Mas, por outro lado, a retórica não racista também calou fundo, no sentido de construir uma confiança possível entre pessoas de diversas cores e origens. Percebi ao longo do livro referências à retórica do não racismo, retórica essa que vai permear fortemente a Frente de Libertação de Moçambique durante e após a guerra. Dizem que os russos perguntaram se Moçambique era de fato um país africano quando Samora Machel apareceu em Moscou com a sua comitiva repleta de jovens filhos de colonos portugueses.

Até hoje Moçambique é muitíssimo menos race conscious que seus vizinhos - África do Sul e Zimbábue. Talvez este seja um de seus trunfos mais importantes na construção de uma identidade nacional viável no interior de um continente que tem sofrido sobremaneira tensões e conflitos entre grupos que reivindicam tradições e culturas distintas.

Moçambique: identidade, colonialismo e libertação é o melhor livro sobre a Independência em Moçambique; aguardamos ansiosos pelo próximo livro de José Luis Cabaço sobre os anos após a Independência até o presente.

\section{BIBLIOGRAFIA}

FREYRE, G. (1953), Aventura e rotina: sugestôes de uma viagem a procura das constantes portuguêsas de caráter e ação. Rio de Janeiro, Livraria José Olympio Editora.

FRY, P. (ed.). (2001), Moçambique, ensaios. Rio de Janeiro, Editora da UFRJ. (2003), "Culturas da diferença: sequelas das políticas coloniais portuguesas e britanicas na África Austral". Afro-Ásia, 29-30, 271-316.

VOGT, C. \& Fry, P. (1996). Cafundó - África no Brasil: linguagem e sociedade. São Paulo, Companhia da Letras. 